\title{
Reimaging Research Methodology as Data Science
}

\section{Ben Kei Daniel}

Educational Technology and Research Methodology, Higher Education Development Centre, University of Otago, Dunedin 9016, New Zealand; ben.daniel@otago.ac.nz

Received: 11 December 2017; Accepted: 3 February 2018; Published: 12 February 2018

\begin{abstract}
The growing volume of data generated by machines, humans, software applications, sensors and networks, together with the associated complexity of the research environment, requires immediate pedagogical innovations in academic programs on research methodology. This article draws insights from a large-scale research project examining current conceptions and practices of academics $(n=144)$ involved in the teaching of research methods in research-intensive universities in 17 countries. The data was obtained through an online questionnaire. The main findings reveal that a large number of academics involved in the teaching of research methods courses tend to teach the same classes for many years, in the same way, despite the changing nature of data, and complexity of the environment in which research is conducted. Furthermore, those involved in the teaching of research methods courses are predominantly volunteer academics, who tend to view the subject only as an "add-on" to their other teaching duties. It was also noted that universities mainly approach the teaching of research methods courses as a "service" to students and departments, not part of the core curriculum. To deal with the growing changes in data structures, and technology driven research environment, the study recommends institutions to reimage research methodology programs to enable students to develop appropriate competences to deal with the challenges of working with complex and large amounts of data and associated analytics.
\end{abstract}

Keywords: big data; research methodology; analytics; data science

\section{Introduction and Related Work}

Research methodology is an essential subject in higher education. The knowledge of research methods and associated tools contribute to the development of an academic discipline. Moreover, the ability to understand and judiciously use data to make useful decisions is one of the essential competencies (post)graduate students are expected to develop. As a field of study, research methodology ought to be concerned with the utilisation of systematic approaches and procedures to investigate well-defined problems, underpinned by a set of specific epistemological and ontological assumptions (Daniel et al. 2017) [1]. Courses on research methods are necessary because they equip students with the essential skills and knowledge needed to solve various problems in the society (Johnson, 1959; Kilburn et al., 2014; Nind et al. 2015; Nayak, 2009) [2-5]. Thus, institutions of higher education are expected to strengthen programs of research methodology to enable students to develop relevant problem-solving and analytical skills for the 21st century (Coetzee and Potgieter 2012; Van der Westhuizen, 2014) [6,7]. However, the current structure and content of many research methods courses cannot adequately support students to acquire the competencies they need to deal with complex data and new analytical tools.

Data complexity manifests itself in terms of "... large scale, high dimensionality, extreme imbalance, online and real-time interaction and processing, cross-media applications, mixed sources, strong dynamics, high frequency, uncertainty, noise mixed with data, unclear structures, unclear hierarchy, heterogeneous or unclear distribution, strong sparsity, and unclear availability of specific sometimes critical data" (Cao, 2017) [8]. 
Since data may be structured or unstructured and may have multiple hierarchies, existing statistical methods (e.g., association, correlation, dependence, and causality theories and systems) cannot adequately handle data complexity (Cao, 2013) [9]. Working with complex data necessitates the development of new methods and analytic tools (Daniel, 2017; Gibson and Ifenthaler, 2017; Ifenthaler, 2016; Metzler et al., 2016) [10-13].

There is a shared agreement that the current pedagogical culture has failed to support evidence-based development and delivery of research methods courses, possibly contributing to the diminishing quality of these courses (Daniel et al., 2017; Kilburn et al., 2014; Wagner et al., 2011) [1,3,14]. The analysis also revealed limited students' input into the complexity of learning research methods courses. Earley (2014) [15] stated that "evidence of students' engagement with research methods courses are largely drawn from teachers' insights and that these teachers are likely to rely on a network of peers and much trial-and-error' when considering developing their pedagogical approach in research methods courses". Nind and Wiles (2014) [3] analysed the literature with the goal of understanding how teachers of research methods courses facilitate students' learning; and identified various forms of pedagogical approaches including active, experiential, and reflexive ways of learning.

Research has consistently identified poor learning outcomes associated with research methods courses (Daniel, 2017; Earley, 2007; Lehtinen and Rui, 1996 Garfield and Ahlgren, 1988, Murtonen, 2015) [1,16-19]. These outcomes are also linked to students' lack of pre-requisite knowledge needed to understand research methods courses upon entering postgraduate education (Lehti and Lehtinen, 2005; Potter, 2003; Winn, 1995) [20-22]. Students' attitudes towards research methods courses also differ, with some questioning the value of these courses after postgraduate education (Williams et al., 2008) [23]. The literature indicated that students are reluctant to take courses on research methods when they cannot see how they will benefit their future careers (Onwuegbuzie, 2000; Onwuegbuzie et al., 2010) [24,25]. Even those who are interested in research methodology are likely to face significant learning problems because of the complex nature of the content of the subject (Benson and Blackman (2003)) [26].

The literature reported variation in the way research methods courses are designed and taught (Murtonen and Lehtinen, 2005; Onwuegbuzie, 2001) [27,28]. There is also a growing tendency within institutions to characterise research methods courses along the qualitative or quantitative conundrum (Franklin, 1997) [29], raising the questions of quality and consistency in teaching courses. The charaterisation of research methods along methodological traditions can lead to preferences given to one particular methodology over another without theoretical or practical justification. Furthermore, this characterisation reinforces the poor practices of designing and delivering research methods, ignoring the value of combining both methods to handle complex data (Gibson and Ifenthaler, 2017) [11].

In addition to the issues of quality in the design of research methods courses, and challenges associated with student learning, Walker and Dimmock (2002) [30] stated that the conventional means of teaching research methods courses need to be updated to cope with changing circumstances of data and the research environment. The evolving nature of various forms of data implies that the current models of the curriculum on research methods are no longer sustainable. Big Data and Data Science, which offer new ways of doing research, also bring new challenges of working with data and design of courses on research methods (Daniel, 2017) [10].

\section{Big Data, Analytics and Data Science}

Big Data refers to the description of characteristics of data (volume, velocity, variety, value and veracity), while analytics refers to the various forms of techniques and approaches used to process, manipulate and generate useful insights or outcomes from data (Daniel, 2015; Manyika, et al., 2011) [10,31]. Big Data and analytics are two critical research paradigms that have emerged in an era where society is rapidly generating data in large volumes. As an emerging paradigm, working with Big Data and analytics requires the knowledge of the 'fourth tradition' (Daniel, 2017) [10]. This fourth tradition is an empirical data-intensive scientific approach, which is ingrained in the fundamental principles of knowledge discovery through data mining and visualization, driven by predictive and actionable analytics. 
Analytics also refers to new tools for data processing and visualization beyond those available in traditional statistics. The use of analytics requires reducing complex data into meaningful and actionable information (Johnson, Levine, Smith, and Stone, 2010) [32].

As a research paradigm, Big Data and analytics requires the use of innovative use of technologies for capturing, storing, distributing, managing and analyzing larger-sized datasets with diverse structures, and visualizing results using dashboards (Daniel, 2017) [10]. Big Data stimulates new ways of framing useful research questions and offering researchers with new sets of innovative methodological techniques for capturing, storing, distributing, managing and analyzing larger-sized datasets (Daniel, 2017) [10].

There are many sources of Big Data; some of the notable ones include institutional statistics, sociometric, sensor data, social media, online transactions data, and historical administrative data (Metzler et al., 2016) [13]. Big Data is also associated with the new forms of digital data generated from social media and learning management systems offer researchers enormous opportunities for extracting meaning (Dede et al., 2016; Doorn, 2014; Lazer, Kennedy, King, and Vespignani, 2014) [33-35].

Working with Big Data research requires an understanding of the fourth research methodology tradition. The fourth tradition is a form of empiricism reflected in the techniques and approaches of research in Data Science (Daniel, 2017) [10]. Moreover, the epistemology associated with Data Science differs from conventional methods (Harford, 2014) [36] because it does not depend on pre-deterministic and hegemonic paradigms, but instead requires a continuous negotiation of meaning constrained by the environment in which the research is carried out.

Unlike the three methodological traditions (quantitative, qualitative, and mixed methods), working with Data Science requires the researchers to deal with complex and heterogeneous data (Fan, Han, and Liu, 2014) [37]. Furthermore, the fourth research methodology tradition (Data Science) appeals to new approaches and procedures for undertaking scientific research in the light of new forms of publically generated data, which can be repurposed and curated within specific regulatory constraints (see Daniel, 2017; Tolle, Tansley, and Hey, 2011) [10,38].

The research presented in this article proposed reimaging research methodology within the context of a Data Science curriculum. The goal is to position research methods courses to respond to the complexity of working with increasing the availability of data and various forms of analytics.

\section{Research Goals}

Research reported in this article is part of a large-scale research project examining current conceptions and practices of academics involved in the teaching of research. The goal of the study was to:

1. explore the reasons for people getting involved in the teaching of research methods courses;

2. understand the general conception of teachers of research methodology about the subject;

3. propose a curriculum framework where research methodology is considered a potential subject of Data Science curriculum.

\section{Methods}

The present research employed a survey design, utilizing an online questionnaire composed of open and closed-ended questions. The study emphasizes a descriptive and interpretative approach to gain a broader understanding of current practices and thinking about the pedagogy of research methodology, and the extent to which research methods courses respond to the changing nature of data generated by machines, applications, sensor networks, people and systems as well as the research environment.

\subsection{Sampling Strategy}

The recruitment process for respondents began with profiling and identifying academics involved in teaching research methodology courses in research-intensive universities $(n=139)$ located in 
17 countries. A total of 200 participants were invited to participate, but only 144 responded to the survey (response rate of $71 \%$; CI 95, 50\% $\pm 4.39 \%$ ). The questionnaire composed of open-ended items and deployed online. The respondents were also geographically distributed. A series of follow-up phone interviews with 10 participants were organised

\subsection{Participants}

The global sample was drawn from research-intensive universities to gather a wide variety of views, with many of the participants employed at universities in Canada (39), Australia (20), UK (18), New Zealand (16), USA (15), and India (15) (see Figure 1). Respondents identified as academics involved in the teaching of research methods courses to a broader range of students, in different disciplines (Word Cloud in Figure 2). The majority identified their academic backgrounds with Social Science (70\%) (See Table 1). Over $40 \%$ of the respondents indicated that they have taught courses on research methods for more than ten years. A significant number of respondents also said they are experts in other fields in addition to research methodology (see Table 1).

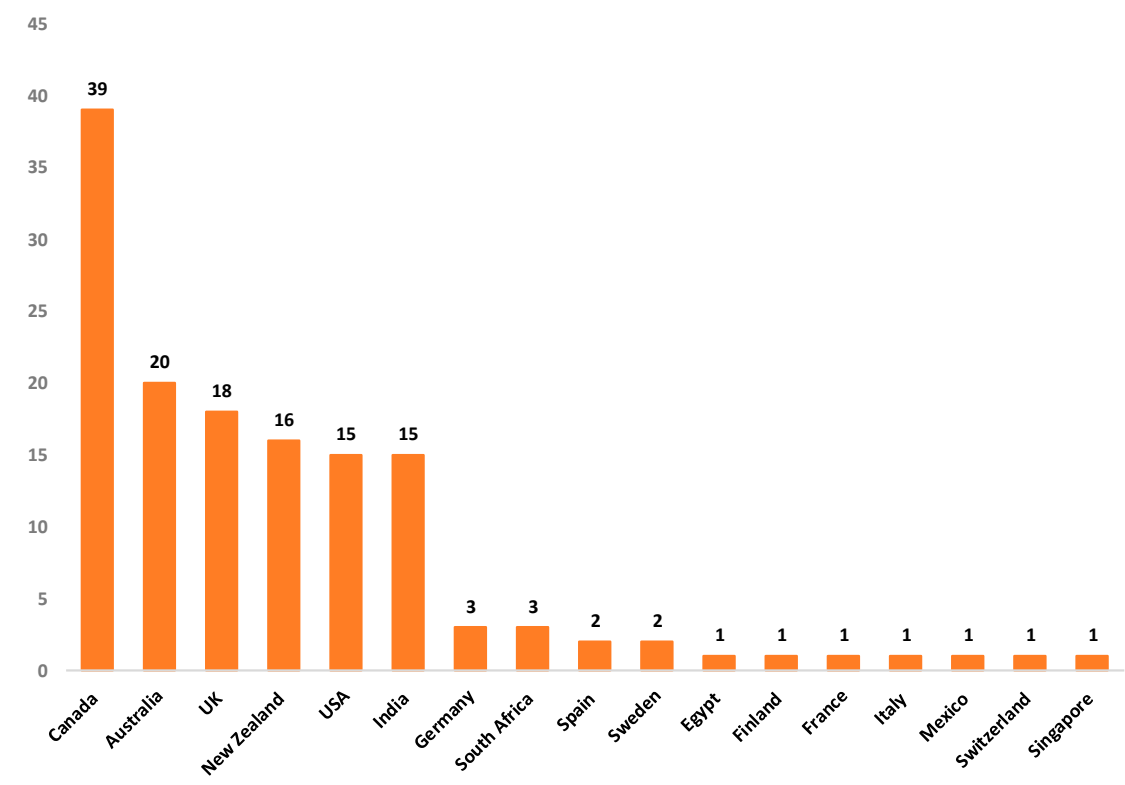

Figure 1. Countries where participants were employed at the time of the research.

Table 1. Participant characteristics.

\begin{tabular}{cc}
\hline Characteristics & $\boldsymbol{n ( \% )}$ \\
\hline Academic background & \\
Social Science & $97(70)$ \\
Natural Sciences & $11(8)$ \\
Health Sciences & $9(7)$ \\
Humanities & $8(6)$ \\
Engineering & $1(1)$ \\
<1 year & $5(4)$ \\
1-5 years & $33(24)$ \\
5-10 years & $45(32)$ \\
More than ten years & $57(41)$ \\
Years of teaching research methods & $73(52)$ \\
How participants predominantly identity & $71(50)$ \\
Subject-matter expert (Biology, Education, etc.) \\
Researcher (Quantitative) & $67(48)$ \\
Researcher (Mixed Methods) & $53(38)$ \\
Researcher (Qualitative) & $45(32)$ \\
Research Methodologist & $2(1)$ \\
Unable to say &
\end{tabular}

Note that some numbers in the table might not add up because some participants identified with different categories and there were also missing values. 


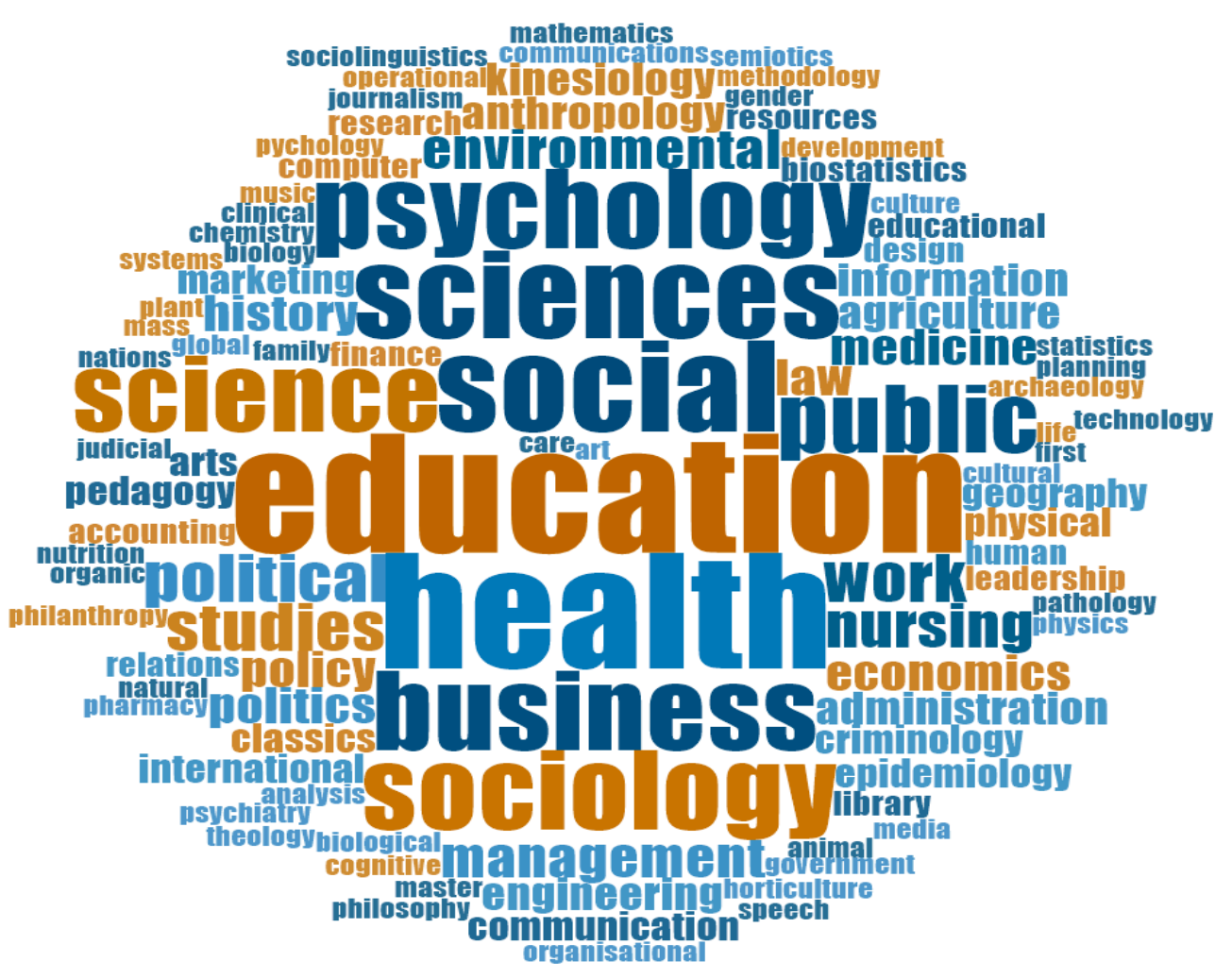

Figure 2. Students' disciplines and subjects.

\section{Data Analysis}

Responses to the open-ended questions in the online questionnaire were analysed inductively and presented as broad themes (Thomas, 2006) [39]. Using the general inductive approach to data analysis responses, responses were extracted and compiled into raw textual data. Themes were identified and linked to the relevant Likert scale questions. The themes were then transformed into a Word cloud. The word cloud provides a visual summary of words that appear more frequently in the body of text (Tong et al., 2012) [40]. Bivariate statistics was used to analyze responses to closed-ended questions (see Table 2).

Respondents were asked to state the disciplines in which they actively taught research methods courses. Data revealed that research methods courses are offered to students from a wide variety of disciplines. However, students in the fields of education, health, psychology, business and sociology seem to dominate as shown in the word cloud, (i.e., the larger the font size the more frequent is the word was mentioned see Figure 2.

\section{Findings and Discussion}

The research presented in this article examined the relevance of the conceptions of current pedagogical design to growing volumes of digital data and the complexity of the research environment. Key findings suggest that research methodology is a complex and technical subject that requires more than a one-semester of teaching and learning. As one participant noted:

Research methodology courses are too much packed into too few hours and are taught by highly biased instructors who teach only methods they favour and give just lip service to alternative approaches.

(Participant-Sociology)

Due to the complexity of the subject, respondents reported that courses on research methods are unpopular among students. Additionally, the study found that many institutions of higher education 
predominantly consider research methodology programs as "service" to other academic departments. The "service" approach to the design and delivery of courses on research methods means that some students do not see research methodology as an important subject on its own, as such others are unlikely to see the relevance of learning research methods courses until the time they start working on their theses (Roberts, 2016) [41], while some would resist taking research methods (Metzler et al., 2016) [13].

Students are uninterested and unmotivated to enrol into research methods classes because often do not see the relevance to their lives unless/until starting thesis—at which point uninterested in any approach which they do not apply in their specific thesis.

(Participant-Education)

Respondents also said that some students view research methods (especially quantitative methods) as a complicated and challenging to learn. As one participant remarked: "research methodology scares the crap out of students, many regards it as toughest course in the program". Since courses on research methods are offered to all students from different disciplines, often faculty teaching these classes come from diverse disciplinary backgrounds, some with expertise outside research methodology, facing a number of challenges teaching the subject.

Analysis of the data show high association between demographic factors and indviduals' approach to teaching research methods courses. For instance, there was a potive correlation between academic background and years spent teaching research methods. Similarly, there was an association between number of years of teaching and those who reported that research methodology should be considered a subject on its own (see table 2).

Table 2. Demographic information and teaching approach.

\begin{tabular}{lccccc}
\hline & AB & YTRM & RMD & PO & PGO \\
\hline 1. Academic background (AB) & & $0.8^{* *}$ & $0.4^{* *}$ & $-0.8^{* *}$ & $-0.9^{* *}$ \\
2. Years teaching research methods (YTRM) & & & $0.8^{* *}$ & $-0.9^{* *}$ & $-0.8^{* *}$ \\
3. Is Research Methodology a discipline on its own? (RMD) & & & & $-0.6^{* *}$ & $-0.5^{* *}$ \\
4. Do you have a personal ontology? (PO) & & & & & $0.9^{* *}$ \\
5. Should postgraduate students be taught ontology? (PGO) & & & & \\
\hline
\end{tabular}

** Correlation is significant at the 0.01 level (2-tailed).

\subsection{Academic Involvement in Teaching Research Methods}

University teachers often teach subjects based on individual expertise, gained through graduate training or professional experience. However, the majority of the teachers of research methods did no acquire formal degrees in the field. Furthermore, only a few considered themselves experts in research methodology. Some teachers of research methods courses are self-taught and seem to acquire methodological expertise by learning on the job. As one participant stated: "I have been interested in learning research methods and enjoy teaching the course. I have done so now at three different universities but still I do not consider myself as an expert".

The study identified five common pathways in which academics are likely to get involved in the teaching of research methods courses(see Table 3). Over a third of the participants in the study stated they were asked by their departments to teach courses on research methods. "I was asked to tutor and then co-coordinate the research methods unit for first years". Others volunteered to teach the subject as one participant pointed out: "the course was available to teach, and I have a passion for research methodology".

Those who had significant experiences as researchers in various disciplines mentioned that their involvement in teaching courses on research methods was primarily based on their experiences. "I worked as a researcher for nine years in educational testing and assessment before being appointed to an academic teaching role with specific responsibility for research methodology".

Over a quarter of the participants indicated that they were trained as research methodologists, and therefore, teaching research methods was within their primary teaching obligations. "I have formal 
training in survey research methods as well as experience in conducting many health surveys. The graduate course I teach is Survey Research Methods". Table 3 presents a summary of data describing shared reasons that led to involvement in teaching courses on research methods.

Table 3. How did you get involved in teaching research methods course?

\begin{tabular}{cc}
\hline Reasons for Involvement $(\boldsymbol{n = 1 1 0 )}$ & Total (\%) \\
\hline I was asked to teach the subject by the department & $34(31)$ \\
I volunteered to teach courses on research methods & $30(28)$ \\
I primarily trained in research methodology & $19(17)$ \\
I am an experienced researcher & $16(15)$ \\
I took some courses in graduate school & $10(9)$ \\
\hline
\end{tabular}

\subsubsection{My Department Asked me to Teach Research Methods}

Those asked by their departments to teach research methods courses reported satisfaction with teaching the subject. However, many said they never anticipated continuing teaching the subject beyond a semester from the time they were requested to teach the subject. As one participant reported: "... becoming a teacher of research methodology, though gratifying was coincidental. I never have thought I would be teaching research methods for that long". Such remarks suggest that the teaching of research methods is by large incidental, and considered a temporary endeavour, even though some participants ended up spending a significant number of years teaching the subject (see, for example, Table 1).

Data suggests lack of consistency across institutions on how the teaching of research methods are assigned, however there seems to be a shared tendency to assign the teaching workload based on availability, interests and to some extent, prior research experience. "The colleague who usually teaches the postgraduate course was on leave, so I stepped in to teach it".

I was approached to develop the course content and for Health Research Methods and Biostatistics for Masters Science students, and Advanced Health Research Methods and Biostatistics for PhD students. Initially, I was assigned to teach these courses on a temporary basis.

\section{(Participant-Health Sciences and Biostatistics)}

First started teaching Research Methods in Physics for Postgraduate students (as a professor of Physics) and once changed the field of work to engineering, I was asked to conduct the same course for engineering students.

(Participant_Engineering Physics)

Participants who were assigned to teach courses on research methods mentioned that teaching those courses provided them with the opportunity to contribute to improving the quality of postgraduate education.

I wanted to increase the rigour of the training in the doctoral program in which I was then employed and so offered to develop a course in research methods for our students.

(Participant-Research Methodology)

\subsubsection{Volunteered to Teach Courses on Research Methods}

Some of the participants who said they volunteered to teach classes on research methods had developed an interest in the subject during postgraduate school. They also reported having taken numerous courses in research methods in postgraduate school.

I have always been primarily interested in (quantitative) research methods, during my undergraduate and graduate studies. I am currently appointed explicitly as a lecturer in social science research methods.

(Participant-Research Methods) 
I had done research; I expressed interest in teaching research methods. Many of my colleagues did not do research and were not that interested in teaching research methods.

(Participant-Education)

Respondents who volunteered to teach courses on research methods reported that they were motivated to advance their knowledge in research methods. They said that volunteering to teach the subject was part of becoming or being "a good department's citizen", and contributed to an enriched research culture in their department.

\subsubsection{Primarily Trained in Research Methodology}

Though there are limited academic programs currently offering postgraduate degrees in Research Methodology, $17 \%$ of the participants reported they were trained research methodologists, and thus consider teaching the subject their primary academic duties.

I have a PhD in Measurement, Evaluation, and Statistical Analysis from the University ... Starting teaching as a teaching assistant, and then continued for 29 years at ... university as a professor of research methodology.

(Participant_-Psychology and Measurement)

\subsubsection{Am an Experienced Researcher}

A small number of participants reported that they were involved in teaching research methods courses because of their experiences in doing research and experience managing large-scale research projects.

I had a long experience as an educational researcher. I was good with numbers. My institution offered a course on quantitative methods with poor success; three teachers were involved in one year; so, I postulated about this post. I obtained it and until now.

\section{(Participant-Education and Teacher Education)}

\subsubsection{Took Postgraduate Courses in Methods}

In most postgraduate education programs students are required to take classes in research methods during their candidacy. Respondents who had had the opportunity to learn all methodological traditions (quantitative, qualitative, and mixed methods) during postgraduate education felt that they had acquired adequate knowledge of research methodologies that enable them to teach the subject very well.

I took many research methods courses over the years, a couple during my undergraduate training in Psychology, another as a Master's student and another during my PhD. When I started as an assistant professor, I was happy to have the opportunity to teach methods.

(Participant_Psychology)

As the data suggest, different reasons led to faculty engagement with teaching research methods. These findings suggest that institutions do not necessarily view research methodology as a subject that requires specific skills to teach. It also implies that some institutions think that anyone with appropriate research experience, interests, and teaching experience can readily teach research methodology irrespective of domain expertise and training.

\subsection{Teachers' General Conception of Research Methodology as a Scholarly Subject}

Respondents were asked: do you consider research methodology as an independent discipline (similar to Mathematics, Statistics or Education)? Responses to this question varied. For some, research methodology is a separate discipline (66\%); others consider it as a program that offers service courses 
to students and academic staff (21\%) and a small number of respondents viewed research methodology as a branch of philosophy ( $7 \%$ ); yet others think it is an interdisciplinary field of inquiry $(6 \%)$.

Those who viewed research methodology as a discipline on its own said that students need to be taught the necessary skills and knowledge they need to undertake a thesis research project, and at the same time be exposed to more than one methodology. Others acknowledge these views, and added that research methodology transcends the application of tools and processes to solve research problems.

I do not think that teaching research methodology is just to solve a research problem that necessitates only a research methodology. I take a more holistic approach to teaching principles of research methods as we are training researchers for future generations, not only for one task.

(Participant-Engineering)

Those who considered research methodology as an interdisciplinary field, mentioned that research methodology is a subject that should not be restricted to a single discipline. "Research methodology cannot be equated to Mathematics, Statistics. It is an essential component of all disciplines".

However, those who viewed research methodology as a sub-discipline of philosophy suggested that the design of research methodology program should draw from logic and calculus to inform the development of scientific methods and procedures for solving problems in the social and material world.

\section{I have written two textbooks on research methodology, and I think it requires an understanding of logic and proof that is nothing to do with a single discipline - it is a branch of philosophy. \\ (Participant-Economics and Marketing)}

The broader conception of research methodology as a "service" subject has influenced the relative identity and value of the subject within academia, and ultimately impacted on the quality of student learning (Daniel, 2017) [1]. Kember (1997) [42] stated that understanding conceptions are essential because teachers' underlying beliefs about a subject can influence how they teach students. Students' motivation to learn the content of a subject partly dependent on the extent to which teachers are inspired about the subject.

As a stand-alone discipline, research methodology is a body of knowledge, concepts, theories, and tools relating to how social and natural systems and entities can be studied. It is concerned with how research questions are framed, essential data is gathered, processed, analysed, interpreted, visualised and managed. Approaching research methodology as a discipline of its own, therefore, requires understanding of research method as a discipline with unique standards, values, language and protocols for engagement among its professionals. It requires those who teach methodology ought to engage in research the field and contributing to its growth and advance.

The present study found out that research methodology occupies a marginal position in many institutions, to the extent that courses on research methods are primarily taught by academic volunteers and amateurs, who view the teaching of these courses as an add-on into other academic commitments. There was evidence that there is inadequate pedagogical innovation in how research methods courses are designed and taught, where programmes are still designed along single research methodological traditions, and students are only taught research skills they need to complete dissertations. As such, courses on research methods serve a short-term goal rather than opportunities for long-term career pathways (Earley, 2014; Howard et al., 2015; Saunders and Bezzina, 2015) [15,43,44], and to a larger extent do not adequately respond to the changing nature of data and the needs and requirements of technology driven complex research environment.

\subsection{Research Methodology as Data Science}

Currently, there is a growing variety of data, generated at in an precedented phase. Data is captured by various instruments, sensors network, simulations, social network, Twitter and other social media data. There is therefore, a need to develop and teach students new and appropriate 
analytical methods to handle the growing volumes of heterogeneous data in unstructured text, audio, and video formats (Daniel, 2017; Gandomi, 2015) [10,45].

Data science is an emergent field of inquiry concerned with the extraction of valuable information from a large and complex set of data, with the purpose discerning valuable knowledge. It involves the use of machine learning and other automated techniques for harvesting, processing, summarization and visualization of data from highly diverse and complex settings. As an interdisciplinary field of inquiry, Data Science draws from the disciplines of Statistics, Computer Science, Operational Research, Mathematics, Humanities and the Social Sciences (see Figure 3). Unlike other areas of applied statistics such as actuarial science, data scientists deal with translating data information and knowledge within a particular context.

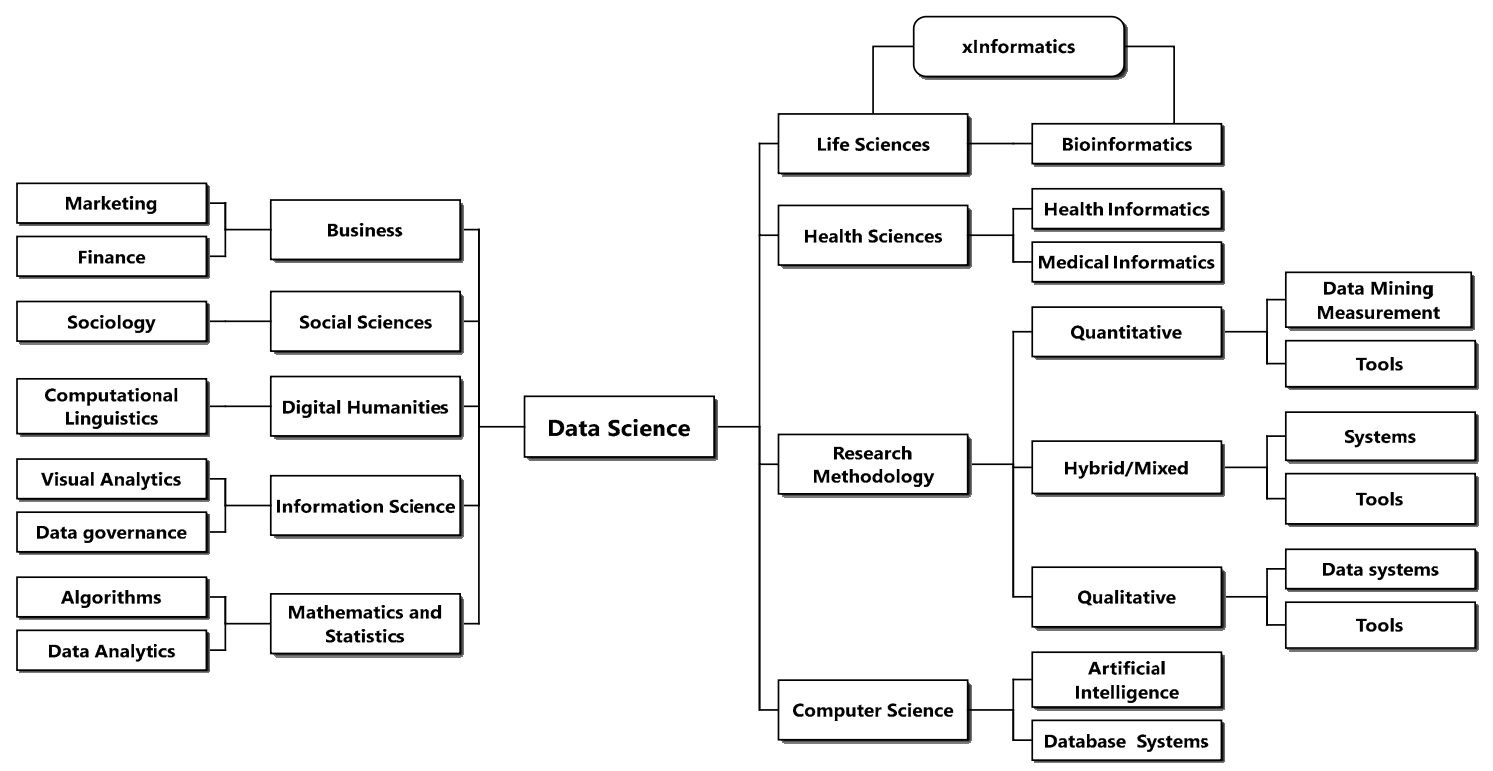

Figure 3. Proposed Data Science and Research Methodology Curriculum.

Data Science is also concerned with the study and development of computational tools, processes, systems, data (structured, semi-structured and unstructured) and models associated with the analysis and management of Big Data. Teaching research methodology within the parametres of Data Science can help students acquire the necessary competence to solve more complex problems of the digital society, and ultimately advancing the scholarly development of research methodology as an independent field of inquiry. The new courses on research methodology need to include concepts on Big Data, analytics, and machine learning approaches.

Research presented in this article aims at raising awareness on the importance of reimaging research methodology in the light of growing data. It questions the extent to which current structure, quality, depth and breadth of the content of current research methods courses offered at institutions of higher education can prepare competent students to work with large sets of data sets and use modern technologies to carry out complex research.

\section{Limitations}

To facilitate better interpretations and contextualization of the insights offered in the article, there are limitations worth pointing out. First, the data presented in the research are mainly perception-based, and reflect the views of those involved in teaching research methods, rather than institutional values, and approaches to the design and development of research methodology programs.

Second, the proposed curriculum framework in which research methodology is considered an area of Data Science is still to be tested. The fact that currently courses on research methods are taught mainly by 
non-specialists suggests that teaching research methodology in the context of Data Science may not be easily tenable in many institutions. In addition, working with Big Data requires access to a significant amount of data, which may not be readily available to institutions (Metzler et al., 2016) [13]. It is also important to note that the subject of Data Science itself is not widely embraced.

Similarly, implementation of Big Data requires distributed computing infrastructure (e.g., Hadoop, MapReduce, and Spark), which might not be accessible to some institutions (Daniel, 2015) [46]. Teaching research methodology within the framework of data science necessitates students learning computer programming and statistical analysis, which many students, especially in the social sciences and humanities may find challenging.

\section{Conclusions}

Research methodology programs provide postgraduate students with the knowledge and abilities to undertake better research, and to provide them with the necessary skills and knowledge to become successful career researchers. However, many institutions take a narrow view of research methodology courses, employing structures and approaches that are inadequate to cater for challenges of working with complex data. Teachers of research methods courses approach research methodology as an isolated set of skills postgraduate students are expected to acquire during their research candidacy, instead of a holistic program that prepares students to become skilled researchers, teachers and future research methodologists.

The article recommends that institutions restructure the design of research methodology programs to reflect the growing complexity in data and the research environment; to better prepare students to work with Big Data and analytics tools (e.g., machine learning techniques and dominant computational approaches). This is achievable through a curriculum transformation in which research methodology is designed and taught within the framework of Data Science. Using such an approach can equip students with the needed competence to work in a data intensive digital society and advance research methodology as a field of inquiry.

Acknowledgments: The research presented here was funded through the New Zealand University Performance Based Funding (PBRF). We also thank all the university teachers who participated and contributed insights and experiences to the project.

Conflicts of Interest: The author declares no conflict of interest.

\section{References}

1. Daniel, B.K. Contestable professional academic identity of those who teach research methodology. Int. J. Res. Method Educ. 2017. [CrossRef]

2. Johnson, V. The value of Research for the Graduate and Postgraduate Medical Student. J. Am. Med. Assoc. 1959, 171, 24-26. [CrossRef] [PubMed]

3. Kilburn, D.; Nind, M.; Wiles, R. Learning as researchers and teachers: The development of a pedagogical culture for social science research methods? Br. J. Educ. Stud. 2014, 62, 191-207. [CrossRef]

4. Nind, M.; Kilburn, D.; Luff, R. The teaching and learning of social research methods: Developments in pedagogical knowledge. Int. J. Soc. Res. Methodol. 2015, 18, 455-461. [CrossRef]

5. Nayak, B.K. Why learn research methodology? Indian J. Ophthalmol. 2009, 57, 173. [CrossRef] [PubMed]

6. Coetzee, M.; Potgieter, I. Undergraduate ODL students' graduateness in relation to their employability attributes and examination preparation styles. Presented at the 1st Unisa International Open Distance Learning Conference, Pretoria, South Africa, 5-7 September 2012.

7. Van der Westhuizen, S. Postgraduate students' attitudes towards research, their research self-efficacy and their knowledge of research. S. Afr. J. High. Educ. 2014, 28, 1414-1432.

8. Cao, L. Data science: Challenges and directions. Commun. ACM 2017, 60, 59-68. [CrossRef]

9. Cao, L. Non-iidness learning in behavioral and social data. Comput. J. 2013, 57, 1358-1370. [CrossRef]

10. Daniel, B.K. Big Data and data science: A critical review of issues for educational research. Br. J. Educ. Technol. 2017. [CrossRef] 
11. Gibson, D.C.; Ifenthaler, D. Preparing the next generation of education researchers for big data in higher education. In Big Data and Learning Analytics in Higher Education; Springer International Publishing: Cham, Switzerland, 2017; pp. 29-42.

12. Ifenthaler, D. Are Higher Education Institutions Prepared for Learning Analytics? TechTrends 2017, 61, 366-371. [CrossRef]

13. Metzler, K.; Kim, D.A.; Allum, N.; Denman, A. Who Is Doing Computational Social Science? Trends in Big Data Research (White Paper); SAGE Publishing: London, UK, 2016. [CrossRef]

14. Wagner, C.; Garner, M.; Kawulich, B. The state of the art of teaching research methods in the social sciences: Towards a pedagogical culture. Stud. High. Educ. 2011, 36, 75-88. [CrossRef]

15. Earley, M.A. A synthesis of the literature on research methods education. Teach. High. Educ. 2014, 19, $242-253$. [CrossRef]

16. Earley, M.A. Lessons Learned from Students' Research Experiences. 2007. Available online: http://jrp.icaap. org/index.php/jrp/article/view/93/75 (accessed on 11 January 2015).

17. Lehtinen, E.; Rui, E. Computer-supported complex learning: An environment for learning experimental methods and statistical inference. Mach. Med. Learn. 1996, 5, 149-175.

18. Garfield, J.; Ahlgren, A. Difficulties in learning basic concepts in probability and statistics: Implications for research. J. Res. Math. Educ. 1988, 19, 44-63. [CrossRef]

19. Murtonen, M. University students' understanding of the concepts empirical, theoretical, qualitative and quantitative research. Teach. High. Educ. 2015, 20, 684-698. [CrossRef]

20. Lehti, S.; Lehtinen, E. Computer-supported Problem-based Learning in the Research Methodology Domain. Scand. J. Educ. Res. 2005, 49, 297-324. [CrossRef]

21. Potter, S.J.; Caffrey, E.M.; Plante, E.G. Integrating service learning into the research methods course. Teach. Sociol. 2003, 31, 38-48. [CrossRef]

22. Winn, S. Learning by doing: Teaching research methods through student participation in a commissioned research project. Stud. High. Educ. 1995, 20, 203-214. [CrossRef]

23. Williams, M.; Payne, G.; Hodgkinson, L.; Poade, D. Does British sociology count? Sociology students' attitudes toward quantitative methods. Sociology 2008, 42, 1003-1021. [CrossRef]

24. Onwuegbuzie, A.J. Statistics anxiety and the role of self-perceptions. J. Educ. Res. 2000, 93, 323-330. [CrossRef]

25. Onwuegbuzie, A.J.; Leech, N.L.; Murtonen, M.; Tähtinen, J. Utilizing mixed methods in teaching environments to reduce statistics anxiety. Int. J. Mult. Res. Approaches 2010, 4, 28-39. [CrossRef]

26. Benson, A.; Blackman, D. Can research methods ever be interesting? Act. Learn. High. Educ. 2003, 4, 39-55. [CrossRef]

27. Murtonen, M.; Lehtinen, E. Conceptions of research and methodology learning. Scand. J. Educ. Res. 2005, 49, 217-224. [CrossRef]

28. Onwuegbuzie, A.J. Critical thinking skills: A comparison of doctoral and masters level students. Coll. Stud. J. 2001, 35, 477-481.

29. Franklin, C. Learning to teach qualitative research: Reflections of a quantitative researcher. Marriage Fam. Rev. 1997, 24, 241-274. [CrossRef]

30. Walker, A.; Dimmock, C. Moving school leadership beyond its narrow boundaries: Developing a crosscultural approach. In Second International Handbook of Educational Leadership and Administration; Springer: Dordrecht, The Netherlands, 2002; pp. 167-202.

31. Manyika, J.; Chui, M.; Brown, B.; Bughin, J.; Dobbs, R.; Roxburgh, C.; Byers, A.H. Big data: the next frontier for innovation, competition, and productivity. Available online: http://www.mckinsey.com/Insights/ MGI/Research/Technology_and_Innovation/Big_data_The_next_frontier_for_innovation (accessed on 12 February 2018).

32. Johnson, L.; Levine, A.; Smith, R.; Stone, S. The 2010 Horizon Report; New Media Consortium: Austin, TX, USA, 2010.

33. Dede, E.; Sendir, B.; Kuzlu, P.; Weachock, J.; Govindaraju, M.; Ramakrishnan, L. Processing Cassandra datasets with Hadoop-streaming based approaches. IEEE Trans. Serv. Comput. 2016, 9, 46-58. [CrossRef]

34. Doorn, P. Big Data in the Humanities and Social Sciences. 2014. Available online: https://sciencenode.org/ feature/big-data-humanities-and-social-sciences.php (accessed on 7 January 2017). 
35. Lazer, D.; Kennedy, R.; King, G.; Vespignani, A. The parable of Google Flu: Traps in significant data analysis. Science 2014, 343, 1203-1205. [CrossRef] [PubMed]

36. Harford, T. Big data: A big mistake? Significance 2014, 11, 14-19. [CrossRef]

37. Fan, J.; Han, F.; Liu, H. Challenges of big data analysis. Natl. Sci. Rev. 2014, 1, 293-314. [CrossRef] [PubMed]

38. Tolle, K.M.; Tansley, D.S.W.; Hey, A.J. The Fourth Paradigm: Data-intensive Scientific Discovery; IEEE: Piscataway, NJ, USA, 2011; pp. 1334-1337.

39. Thomas, D.R. A General Inductive Approach for Analyzing Qualitative Evaluation Data. Am. J. Eval. 2006, 27, 237-246. [CrossRef]

40. Tong, A.; Flemming, K.; McInnes, E.; Oliver, S.; Craig, J. Enhancing transparency in reporting the synthesis of qualitative research: ENTREQ. BMC Med. Res. Methodol. 2012, 12, 181. [CrossRef] [PubMed]

41. Roberts, L.D. Editorial: Research Methods Pedagogy: Engaging Psychology Students in Research Methods and Statistics. Front. Psychol. 2016, 7, 1430. [CrossRef] [PubMed]

42. Kember, D. A reconceptualisation of the research into university academics' conceptions of teaching. Learn. Instr. 1997, 7, 255-275. [CrossRef]

43. Howard, C.; Brady, M. Teaching social research methods after the critical turn: Challenges and benefits of a constructivist pedagogy. Int. J. Soc. Res. Methodol. 2015, 18, 511-525. [CrossRef]

44. Saunders, M.N.; Bezzina, F. Reflections on conceptions of research methodology among management academics. Eur. Manag. J. 2015, 33, 297-304. [CrossRef]

45. Gandomi, A.; Haider, M. Beyond the hype: Big data concepts, methods, and analytics. Int. J. Inf. Manag. 2015, 35, 137-144. [CrossRef]

46. Daniel, B. Big Data and analytics in higher education: Opportunities and challenges. Br. J. Educ. Technol. 2015, 46, 904-920.

(C) 2018 by the author. Licensee MDPI, Basel, Switzerland. This article is an open access article distributed under the terms and conditions of the Creative Commons Attribution (CC BY) license (http://creativecommons.org/licenses/by/4.0/). 